\title{
The chemokine CXCL1 induces proliferation in epithelial ovarian cancer cells by transactivation of the epidermal growth factor receptor
}

\author{
Christine Bolitho, Michael A Hahn, Robert C Baxter and Deborah J Marsh
}

Hormones and Cancer Group, Kolling Institute of Medical Research, Royal North Shore Hospital, University of Sydney, E25, St Leonards, New South Wales 2065, Australia

(Correspondence should be addressed to D J Marsh; Email: deborah.marsh@sydney.edu.au)

\begin{abstract}
The chemokine CXCL1 is elevated in plasma and ascites from patients with ovarian cancer. We have previously shown that CXCL1 is a marker of phosphatidylinositol 3-kinase signalling in epithelial ovarian cancer (EOC) cell lines, a pathway that is commonly activated in ovarian tumours. To investigate whether CXCL1 also has functional significance in ovarian cancer, this chemokine was either down-regulated using siRNAs or overexpressed by transfection of CXCL1 into the EOC cell lines SKOV3 and OVCAR-3 and proliferation assessed over 7 days. Overexpression of CXCL1 increased proliferation of ovarian cancer cells over 7 days, while down-regulation was inhibitory. Treatment of cells with recombinant CXCL1 induced epidermal growth factor receptor (EGFR) phosphorylation at Y1068, indicating crosstalk between the CXCL1 G-protein-coupled receptor CXCR2 and the EGFR. CXCL1-induced proliferation was also decreased by inhibition of EGFR kinase activity and was dependent on extracellular matrix metalloproteinase-mediated release of heparin-binding EGF (HB-EGF). Involvement of mitogenactivated protein kinase (MAPK)/extracellular signal-regulated kinase 1/2 (ERK1/2) signalling was also evident since inhibition of both Ras and MEK activity decreased CXCL1-induced proliferation. CXCL1-induced ERK1/2 phosphorylation was inhibited by the MEK1 inhibitor PD98059; however, EGFR phosphorylation was unaffected, indicating that CXCL1 activation of MAPK signalling is downstream of the EGFR. Taken together, these data show that CXCL1 functions through CXCR2 to transactivate the EGFR by proteolytic cleavage of HB-EGF, leading to activation of MAPK signalling and increased proliferation of EOC cells.
\end{abstract}

Endocrine-Related Cancer (2010) 17 929-940

\section{Introduction}

Ovarian cancer accounts for $\sim 4 \%$ of cancers in women and has the highest mortality rate of the gynaecological malignancies (Schildkraut \& Thompson 1988, Parkin et al. 2005). Five year survival is $<30 \%$ for patients with late stage disease, but increases to around $90 \%$ for women diagnosed in the early stages of this disease (Jacobs \& Menon 2004). Currently, the most common test used to aid in the diagnosis of epithelial ovarian cancer (EOC) is serum measurement of the glycoprotein CA-125. While this test has high sensitivity, it also has low specificity (Bast et al. 1983, Jacobs \& Bast 1989, Jacobs \& Menon 2004).
Factors explored as potential serum markers of ovarian cancer include insulin-like growth factor binding protein-2 (Baron-Hay et al. 2004), interleukin 7 (IL7; Lambeck et al. 2007) and more recently, the combined use of $\beta_{2}$-microglobulin, apolipoprotein A-1, transthyretin, and transferrin with CA-125, significantly improving the detection of early stage ovarian cancer (Kozak et al. 2005, Nosov et al. 2009, Fung 2010). This has led to development of the FDA-approved Ovarian Tumour Triage Test, known as OVA1 (Vermillion, Fremont, CA, USA), which is recommended for use in conjunction with imaging and physical examination, but not as an isolated diagnostic test (Fung 2010). 
The phosphatidylinositol 3-kinase (PI3-K) signalling pathway is commonly activated in EOC, and many of its components are implicated in increased cell survival and proliferation (Shayesteh et al. 1999). We recently investigated the involvement of PI3-K signalling in the regulation of secreted proteins in EOC cells by proteomic profiling using surface-enhanced laser desorption/ionisation time-of-flight mass spectrometry (SELDI-TOF MS), and identified the chemokine (C-X-C motif) ligand 1 (CXCL1) as a marker of $\mathrm{PI} 3-\mathrm{K}$ signalling in conditioned media from five EOC cell lines (Moscova et al. 2006).

CXCL1, also known as melanoma growth stimulating activity or Gro- $\alpha$, is a member of the CXC chemokine family that binds to and activates the G-protein-coupled receptor (GPCR) CXCR2 (Balkwill 2004). This chemokine was first isolated from the human melanoma cell line HSO294 (Richmond et al. 1983) and subsequently from human melanoma tumours (Richmond \& Thomas 1988), and promotes tumour progression (Richmond et al. 1983, 1985, Bordoni et al. 1989, 1990, Shattuck et al. 1994, Luan et al. 1997).

CXCL1 has been implicated in normal ovulation and is detected in follicular fluid as well as in ovarian stromal and granulosa lutein cells (Oral et al. 1997, Karstrom-Encrantz et al. 1998). In ovarian cancer cells, CXCL1 is up-regulated by MTA1, a metastasisassociated gene (Dannenmann et al. 2008), lysophosphatidic acid (Lee et al. 2006) and Ras (Yang et al. 2006). In addition, elevated CXCL1 has been reported in plasma, serum, ascites and tumour tissue of ovarian cancer patients (Lee et al. 2006, Yang et al. 2006, Wang et al. 2008). Since CXCL1 is up-regulated in ovarian cancer (Moscova et al. 2006), we sought to determine whether elevated levels of this chemokine might have an autocrine role in EOC by influencing cell growth via key signalling pathways.

Recent reports have demonstrated that many GPCR agonists may induce transactivation of the epidermal growth factor receptor (EGFR), suggesting crosstalk between chemokine and growth factor pathways to induce proliferation (Carpenter 1999, 2000, Bhola \& Grandis 2008, Liebmann 2010). One mechanism of EGFR transactivation by GPCRs is through the matrix metalloproteinase (MMP)-mediated release of membrane-bound EGFR ligands, such as heparin-binding EGF-like growth factor (HB-EGF), that subsequently activate the EGFR (Prenzel et al. 1999, Schafer et al. 2004). The EGFR can also be transactivated intracellularly via Src signalling (Andreev et al. 2001, Guerrero et al. 2004, Li et al. 2006). Since CXCL1 signalling occurs through a GPCR, we investigated whether CXCL1 may transactivate the EGFR, leading to increased proliferation in EOC.

\section{Materials and methods}

\section{Cell lines and reagents}

The human EOC cell lines SKOV3 and OVCAR-3 were obtained from the American Type Culture Collection (Manassas, VA, USA). Anti-human HB-EGF neutralising antibodies were obtained from $R \& D$ Systems (Minneapolis, MN, USA), and rabbit anti-phospho-EGFR (Y1068) was purchased from Invitrogen Australia. Rabbit anti-total EGFR, total Akt and phospho-Akt (S473), total extracellular signalregulated kinase 1/2 (ERK1/2), phosphorylated ERK1/2, total Src, phospho-Src (Y416) and phosphoSrc (Y527), phospho-EGFR (Y845) and phosphoEGFR (Y1173) were obtained from Cell Signalling Technology (Beverly, MA, USA). Inhibitors SB225002, PD98059, PD153035 and GM6001 were purchased from Calbiochem (San Diego, CA, USA), and FTI-277 was purchased from Sigma-Aldrich. Two sources of human recombinant CXCL1 were used: Millipore (North Ryde, NSW, Australia: discontinued) and R\&D Systems. EGF and protease inhibitor cocktail (cat \#P8340) were purchased from Sigma-Aldrich. Amaxa Cell Line Nucleofector Kit V from Lonza Cologne AG was purchased from Quantum Scientific (Lane Cove, NSW, Australia). Enhanced chemiluminescence (ECL) reagents, Supersignal West Dura extended duration and Pico chemiluminescent substrate reagents were obtained from Thermoscientific (Rockford, IL, USA). Restriction enzymes BspTI (AfIII) and Not1 were obtained from Fermentas Life Sciences (Burlington, Ont., Canada).

\section{Cell culture}

SKOV3 and OVCAR-3 cells were cultured in RPMI 1640 medium (Gibco, Invitrogen) supplemented with $10 \%$ FCS (Gibco or SAFC Biosciences, Brooklyn, VIC, USA) and $0.3 \mathrm{mg} / \mathrm{l}$ glutamine (Gibco) at $37^{\circ} \mathrm{C}$ in $5 \% \mathrm{CO}_{2}$.

\section{Overexpression of CXCL1}

Sense and antisense oligonucleotides were designed to amplify CXCL1 cDNA: forward 5'-TAATCTTAAGATGGCCCGCGCTGCTCTCTC-3' and reverse 5'-TGCTGCGGCCGCTCAGTTGGATTTGTCACTGT-3' (Sigma-Aldrich). CXCL1 cDNA was PCR amplified from RNA extracted from the prostate cancer cell line PC3 using AccuPrime Pfx (Invitrogen). The BspTI (AflII) site (underlined) within the forward primer and the Not1 site (underlined) in the reverse primer were used to directionally clone the PCR product into the mammalian expression vector pcDNA4/TO 
(Invitrogen). Integrity of the pcDNA4/CXCL1 construct was verified by sequence analysis (Supamac, Sydney University, NSW, Australia) with CXCL1 sequence compared with NCBI Genbank Accession number NM_001511.2. To determine the effect of CXCL1 overexpression upon proliferation of ovarian cancer cells, $1.0 \times 10^{6}$ SKOV3 or OVCAR-3 cells were transfected with $5 \mu \mathrm{g}$ of empty vector or pcDNA4/CXCL1 by nucleofection (Nucleofector Kit V, program V-005 for SKOV3 cells and program A-023 for OVCAR-3 cells; Lonza Cologne AG, Germany).

\section{siRNA down-regulation of CXCL1}

siRNA targeted against CXCL1 was custom designed by Qiagen (HP Guaranteed siRNA: target mRNA sequence: 5'-CAGUGUUUCUGGCUUAGAA-3'). A generic non-silencing siRNA with no known sequence homology (target mRNA sequence: 5'-UUCUCCGAACGUGUCACGU-3'; Qiagen) was used as a negative control. In total, $1.0 \times 10^{6}$ SKOV3 or OVCAR-3 cells were transfected by nucleofection with $2 \mu \mathrm{M}$ of either CXCL1 or non-silencing siRNA (Nucleofector Kit V, program V-005 for SKOV3 cells and program A-023 for OVCAR-3 cells).

Down-regulation of CXCL1 mRNA was assessed by quantitative real-time PCR (qRT-PCR) using Taqman Gene Expression Assays (CXCL1: HS00236937_m1; Applied Biosystems, Foster City, CA, USA) and Taqman Universal PCR Master Mix, No AmpErase UNG (Applied Biosystems) on a Rotor-Gene 3000 thermal cycler (Corbett Research, Mortlake, NSW, Australia). The reference gene hydroxymethylbilane synthase (HMBS; Hs00609297_m1) was used for normalisation, and results were expressed as CXCL1:HMBS. Assays were performed in triplicate, and data were analysed using the $\Delta \Delta C_{\mathrm{t}}$ method (RotorGene 6 Analysis Software; Corbett Life Sciences) expressed relative to non-silencing control siRNAtransfected samples.

\section{Proliferation assays}

SKOV3 and OVCAR-3 cells transfected with siRNA, CXCL1 expression construct or empty vector as described above were plated at $1.0-2.0 \times 10^{4}$ cells per well into 48 -well tissue culture plates. Proliferation was assessed by direct cell counts at days 2, 4 and 7, expressed as relative cell numbers with the total number of cells on day 7 for either non-silencing siRNA-transfected cells or empty vector-transfected cells expressed as 100. At each time point, the concentration of secreted CXCL1 in cultured supernatants was monitored using a Human CXCL1/Gro- $\alpha$
Quantikine sandwich ELISA kit (R\&D Systems), according to the manufacturer's instructions. Data were calculated as fold difference relative to CXCL1 concentration in the non-silencing siRNA- or empty vector-transfected control at day 2. A Human IL8 Quantikine sandwich ELISA kit was also purchased from R\&D Systems.

\section{Signalling pathways}

SKOV3 and OVCAR-3 cells were plated in triplicate into 48 -well tissue culture plates at $1.0-2.0 \times 10^{4}$ cells/well and treated with recombinant CXCL1 alone $(100 \mathrm{ng} / \mathrm{ml}$ in $10 \%$ FCS media) or recombinant CXCL1 in the presence of either CXCR2 inhibitor SB225002 (200 nM), EGFR inhibitor PD153035 $(100 \mathrm{nM})$, MEK1 inhibitor PD98059 $(10 \mu \mathrm{M})$, farnesyltransferase inhibitor FTI-277 $(10 \mu \mathrm{M})$, pan-MMP inhibitor GM6001 (200 nM) or HB-EGF neutralising antibody $(4 \mu \mathrm{g} / \mathrm{ml})$. In some experiments, gefitinib (200 nM; AstraZeneca, Macclesfield, UK) was alternatively used to inhibit EGFR kinase activity. EGF $(50 \mathrm{ng} / \mathrm{ml})$ was used as a positive control in experiments investigating transactivation of the EGFR by CXCL1. Untreated and inhibitor-only controls were included, and treatments replenished every 2-3 days.

\section{Western blot analysis}

SKOV3 cells were seeded into 6-well tissue culture plates $\left(2.0 \times 10^{5}\right.$ cells/well $)$ for $24 \mathrm{~h}$, serum starved in media containing $0.5 \%$ BSA for a further $24 \mathrm{~h}$, then stimulated with recombinant CXCL1 $(100 \mathrm{ng} / \mathrm{ml})$ for up to $120 \mathrm{~min}$. A 5-min treatment of cells with EGF $(50 \mathrm{ng} / \mathrm{ml})$ was used as a positive control for EGFR phosphorylation. For experiments investigating mitogen-activated protein kinase (MAPK) signalling, SKOV3 cells were pretreated with PD98059 $(10 \mu \mathrm{M})$ for $30 \mathrm{~min}$ before treatment with CXCL1 $(100 \mathrm{ng} / \mathrm{ml})$ for 5-120 $\mathrm{min}$ or EGF $(50 \mathrm{ng} / \mathrm{ml})$ for $5 \mathrm{~min}$. After treatment, cells were washed with ice-cold PBS and lysed in $200 \mu \mathrm{l}$ of chilled SDS sample buffer $(62.5 \mathrm{mM}$ Tris (pH 6.8)), $20 \mathrm{~g} / \mathrm{l} \mathrm{SDS,} 10 \%$ glycerol, $50 \mathrm{mM}$ dithiothreitol and $0.01 \%$ bromophenol blue containing $1 \% \mathrm{v} / \mathrm{v}$ protease inhibitor cocktail (Sigma-Aldrich) at $4{ }^{\circ} \mathrm{C}$ for $10 \mathrm{~min}$. Cell lysates were sonicated for $30 \mathrm{~s}$, and proteins were separated using $4-12 \%$ Bis-Tris SDS-PAGE gels (Invitrogen) and transferred to Hybond C nitrocellulose (GE Healthcare Life Sciences, Rydalmere, NSW, Australia) for western analysis. After transfer, membranes were blocked using 5\% milk in Tris-buffered saline-T (TBS-T; $20 \mathrm{mM}$ Tris- $\mathrm{HCl}, \mathrm{pH} 7.5,150 \mathrm{mM} \mathrm{NaCl}$ and $0.1 \%$ Tween 20) and probed with primary antibodies diluted 
in TBS-T containing 5\% BSA overnight at $4{ }^{\circ} \mathrm{C}$. Membranes were washed with TBS-T for $1 \mathrm{~h}$ before incubating with a HRP-conjugated secondary antibody (diluted 1:5000 in 5\% milk in TBS-T) for $1 \mathrm{~h}$ at room temperature before washing again in TBS-T and detection of bound antibodies by ECL using SuperSignal West Pico and Dura substrates (Pierce, Rockford, IL, USA). Total and phosphorylated proteins were analysed on replicate blots. Membranes were also probed with $\alpha$-tubulin antibody as a loading control. Images were recorded using the FujiFilm LAS-4000 imaging system (Berthold Australia Pty Ltd, Bundoora, VIC, Australia). Densitometry of bands was performed using Multigauge software (v3.0; Fujifilm Australia Pty Ltd, Brookvale, NSW, Australia), and data were expressed as the ratio of phosphorylated to total protein.

\section{Statistical analysis}

Data analyses were performed using SPSS software 16.0 (SPSS Australasia Pty Ltd, Chatswood, NSW, Australia). Data are expressed as mean \pm s.E.M. from at least three independent experiments. Statistical significance for western blot analysis and proliferation experiments was determined by one-way ANOVA and repeated-measures ANOVA respectively. $P<0.05$ was considered statistically significant.

\section{Results}

\section{Overexpression of CXCL1 increases EOC cell proliferation}

To investigate whether CXCL1 influenced EOC cell proliferation, a CXCL1 expression construct was transfected into SKOV3 and OVCAR-3 cells and proliferation assessed over 7 days. Relative to empty vector control, CXCL1 overexpression led to increased cell proliferation in both cell lines: for SKOV3, $38.9 \pm 16.9 \%$ increase at day $7(P<0.005)$; for OVCAR-3, 53.6 $\pm 3.6 \%$ increase $(P<0.05$; Fig. 1A and B). Secreted CXCL1 in CXCL1-transfected cells also increased over this time period relative to empty vector. At day 7, SKOV3-secreted CXCL1 levels in empty vector cells were $40.2 \pm 4.4 \mathrm{ng} / \mathrm{ml}$ compared to $77.1 \pm 9.0 \mathrm{ng} / \mathrm{ml}$ in cells transfected with the CXCL1 construct $(P<0.001)$; OVCAR-3-secreted CXCL1 levels in empty vector cells were $2.2 \pm 0.9 \mathrm{ng} / \mathrm{ml}$ compared to $98.4 \pm 37.4 \mathrm{ng} / \mathrm{ml}$ in cells transfected with the CXCL1 construct $(P<0.002$; Fig. $1 \mathrm{C}$ and D).
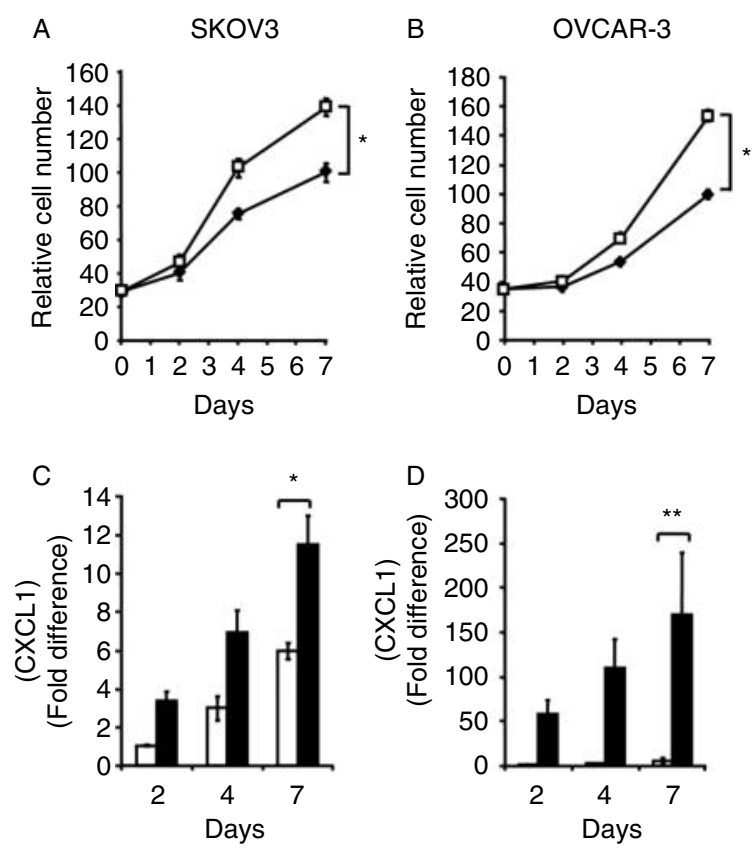

Figure $1 \mathrm{CXCL} 1$ overexpression induces proliferation of ovarian cancer cells. Cellular proliferation over 7 days (A and B) and concentration of CXCL1 in cell culture supernatants (C and D) were assessed in SKOV3 (A and C) and OVCAR-3 (B and D) cells. Graphs represent pooled data of four independent experiments with data expressed as mean relative cell number \pm S.E.M. where total cell number in empty vectortransfected control (day 7 ) is expressed as 100 (A and B), or calculated as fold difference \pm s.E.M. relative to CXCL1 concentration in empty vector-transfected control (day 2) $(C$ and $D)$. There was an increased proliferation over 7 days in SKOV3 (A) and OVCAR-3 (B) cells transfected with pcDNA4/CXCL1 (square) compared with pCDNA4/TO (diamond). This corresponded to an increase in secreted CXCL1 in cell culture supernatants $(C$ and $D)$ (pcDNA4/TO, open bars; pcDNA4/CXCL1, closed bars). ${ }^{\star} P<0.001,{ }^{\star \star} P<0.002$.

\section{Down-regulation of CXCL1 reduces EOC cell proliferation}

As overexpression of CXCL1 increased proliferation of ovarian cancer cells, we investigated whether down-regulation of CXCL1 by siRNA would reduce proliferation. Approximately $60 \%$ of CXCL1 transcript was down-regulated by CXCL1 siRNA at day 3 in both SKOV3 and OVCAR-3 cells (Supplementary Figure 1, see section on supplementary data given at the end of this article and data not shown). Secreted CXCL1 in cells transfected with CXCL1 siRNA was decreased relative to cells transfected with a nonsilencing siRNA in both cell lines: for SKOV3, 70.2 $\pm 3.8 \%$ reduction (day 2 ), $61.5 \pm 7.1 \%$ (day 4 ) and $58.0 \pm 4.8 \%$ (day 7); for OVCAR-3, $80.5 \pm 4.2 \%$ reduction (day 2), $71.4 \pm 2.1 \%$ (day 4) and 58.8 $\pm 11.6 \%$ (day 7) (Fig. 2A and B). We had previously shown that IL8, also known as CXCL8, is a secreted 
marker of PI3-K signalling in EOC cell lines (Moscova et al. 2006). Like CXCL1, IL8 signals through the receptor CXCR2. Down-regulation of CXCL1 did not affect secreted levels of IL8 (Supplementary Figure 2, see section on supplementary data given at the end of this article).

A reduction in cellular proliferation was observed over 7 days in both cell lines following downregulation of CXCL1 by siRNA compared to control cells (Fig. 2C and D; $P<0.0001$ ). Addition of recombinant CXCL1 $(100 \mathrm{ng} / \mathrm{ml})$ to CXCL1 siRNAtransfected cells restored proliferation to levels similar
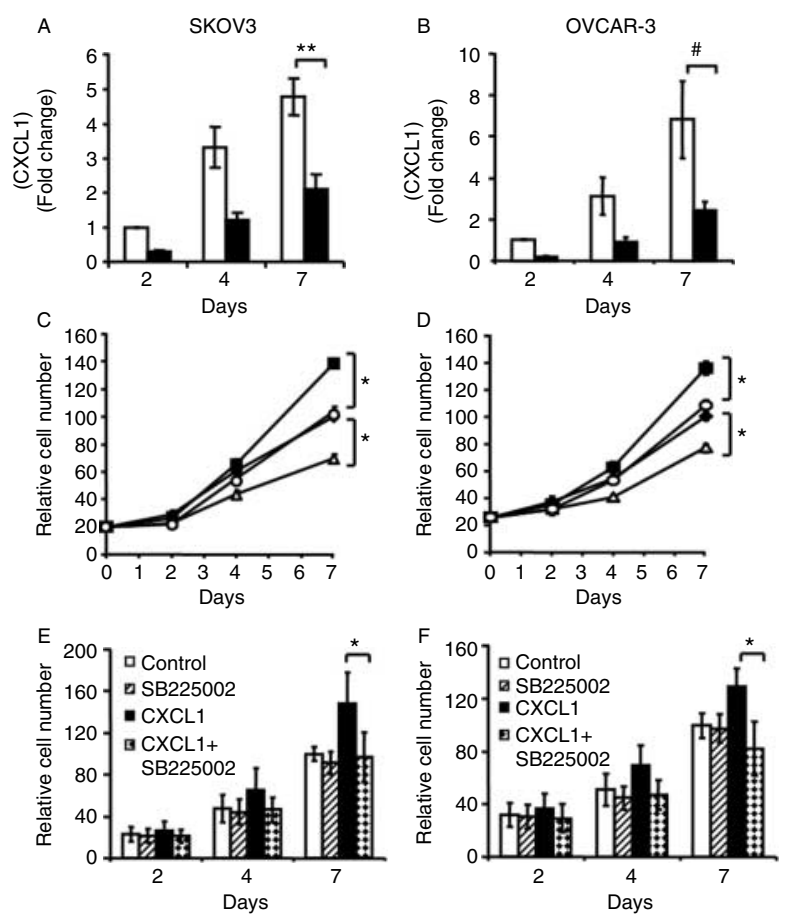

Figure 2 Down-regulation of CXCL1 decreases proliferation of ovarian cancer cells. Concentration of CXCL1 in cell culture supernatants (A and $B$ ) and cellular proliferation over 7 days (C and D) were assessed in SKOV3 (A and C) and OVCAR-3 ( $B$ and $D$ ) cells following down-regulation of CXCL1 by siRNA. Graphs represent pooled data from four independent experiments calculated as fold difference \pm S.E.M. relative to CXCL1 concentration in the negative siRNA control at day 2 ( $A$ and $B$ ), or expressed as mean relative cell number \pm s.E.M. where total cell number in the negative siRNA control at day 7 is expressed as $100(C$ and $D)$. (A and $B$ ) Secreted $C X C L 1$ in cells transfected with CXCL1 siRNA (closed bars) was decreased relative to cells transfected with non-silencing siRNA (open bars). (C and D) Down-regulation of CXCL1 (triangle) resulted in a reduction of cellular proliferation when compared to control cells (diamond). Addition of recombinant CXCL1 to CXCL1 siRNA down-regulated cells (circle) restored proliferation to levels seen in control cells, while a further increase in proliferation was observed when CXCL1 was added to cells transfected with non-silencing siRNA (square). ( $E$ and $F$ ) CXCL1-induced proliferation of SKOV3 (E) and OVCAR-3 (F) cells was inhibited by blocking CXCR2 using SB225002 (200 nM). ${ }^{\star} P<0.00001,{ }^{\star \star} P<0.001,{ }^{\#} P<0.05$. to that seen in control cells, while a further increase in proliferation was observed when recombinant CXCL1 $(100 \mathrm{ng} / \mathrm{ml})$ was added to cells transfected with the non-silencing siRNA in both cell lines $(P<0.00001$; Fig. 2C and D).

To confirm the receptor dependence of CXCL1 action, SKOV3 and OVCAR-3 cells were stimulated with recombinant CXCL1 $(100 \mathrm{ng} / \mathrm{ml})$ either in the presence or absence of the CXCR2 inhibitor, SB225002 $(200 \mathrm{nM})$ and cell proliferation assessed over 7 days. CXCL1-induced proliferation at day 7 in both cell lines was inhibited by SB225002 $(P<0.0001$; Fig. 2E and F), confirming that CXCL1-induced proliferation is mediated through CXCR2.

\section{Transactivation of the EGFR by CXCL1}

To investigate possible crosstalk between CXCR2 and the EGFR, SKOV3 and OVCAR-3 cells were stimulated with recombinant CXCL1 $(100 \mathrm{ng} / \mathrm{ml})$ in the presence of the EGFR inhibitor PD153035 $(100 \mathrm{nM})$. Cells were also stimulated with EGF $(50 \mathrm{ng} / \mathrm{ml})$ as a positive control. CXCL1-induced proliferation in both cell lines was completely blocked by inhibition of EGFR kinase activity $(P<0.0001$; Fig. 3A and B). A similar result was seen with an alternative EGFR inhibitor (gefitinib, $200 \mathrm{nM}$; data not shown). Stimulation of SKOV3 cells with recombinant CXCL1 $(100 \mathrm{ng} / \mathrm{ml})$ induced a peak of EGFR tyrosine phosphorylation at Y1068 which was significant at $5 \mathrm{~min}(P<0.05)$ but not at $15 \mathrm{~min}$, exhibiting a second wave of phosphorylation reaching a twofold increase at 120 min $(P<0.0002$; Fig. 3C and D). This biphasic response was observed in four of six experiments. Furthermore, CXCL1-induced phosphorylation at Y1068 was inhibited by treatment with either the pan-MMP inhibitor GM6001 or the EGFR inhibitor PD153035 (Supplementary Figure 3, see section on supplementary data given at the end of this article).

Increased phosphorylation at Y1068 could not be robustly determined in OVCAR-3 cells as the phosphorylation signal detected by western blot was only weakly detectable under conditions where it was observed in SKOV3 cells. EGFR phosphorylation at Y845 and Y1173 was not observed in SKOV3 cells in response to stimulation with CXCL1; however, these sites were phosphorylated in response to treatment with EGF (Supplementary Figure 4, see section on supplementary data given at the end of this article). Taken together, this suggests that CXCL1-induced proliferation of EOC cells is mediated through EGFR transactivation. 

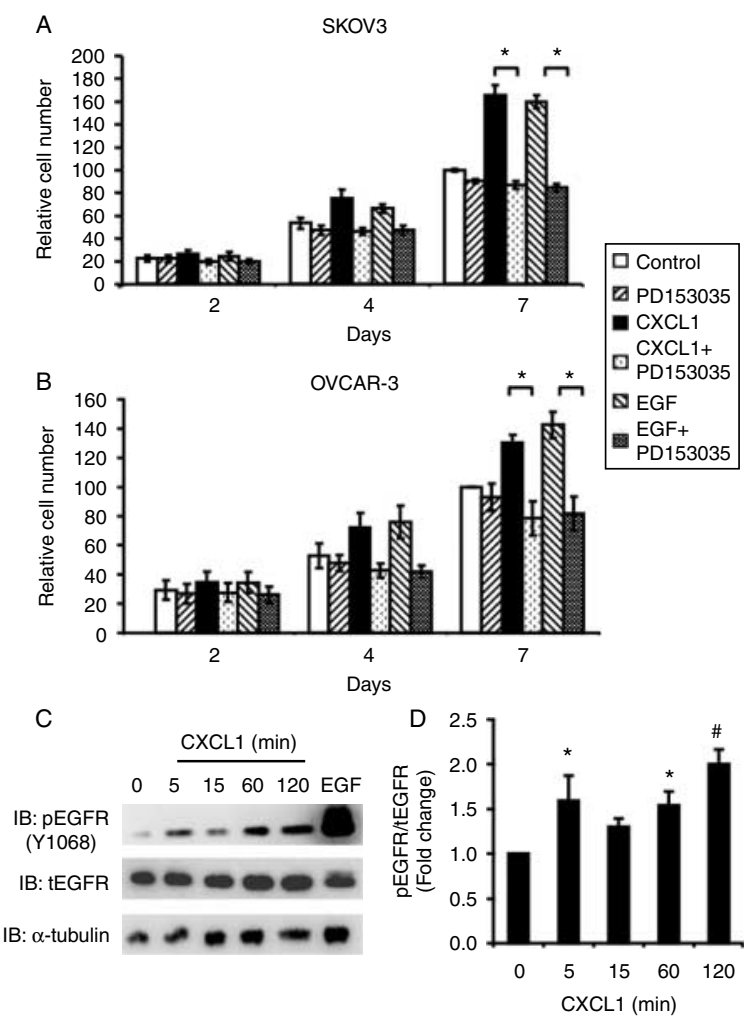

Figure 3 CXCL1 induces proliferation via EGFR transactivation. The effect of EGFR inhibition upon CXCL1-induced proliferation was assessed in SKOV3 (A) and OVCAR-3 (B) cells. Graphs represent pooled data from three independent experiments expressed as mean relative cell number \pm S.E.M. where total cell number in the untreated control at day 7 is expressed as 100. CXCL1-induced proliferation was decreased in the presence of the EGFR inhibitor, PD153035 (100 nM). EGF $(50 \mathrm{ng} / \mathrm{ml})$ was included as a positive control for stimulation of the EGFR, ${ }^{*} P<0.0001$. (C and D) Serumdeprived SKOV3 cells were treated with CXCL1 $(100 \mathrm{ng} / \mathrm{ml})$ for 5-120 min. Cell lysates were immunoblotted for phosphorylated EGFR (pEGFR) (Y1068), total EGFR (tEGFR) and $\alpha$-tubulin expression (C). Graph represents pooled data from six independent experiments, calculated as $\mathrm{pEGFR/tEGFR} \mathrm{ratios}$ and expressed as fold change relative to untreated control \pm S.E.M. (D). CXCL1 induced phosphorylation of the EGFR at Y1068 in a time-dependant and biphasic manner, ${ }^{\star} P<0.05$, ${ }^{\#} P<0.0002$ (treated versus untreated control).

Since CXCL1 expression is induced by PI3-K pathway activation and EGFR signalling activates PI3-K in ovarian cancer cell lines (Moscova et al. 2006), the possibility of a positive feedback loop occurring where CXCL1 regulates its own production by also activating PI3-K signalling was investigated. Serum-deprived SKOV3 cells were treated with CXCL1 (100 ng/ml) for 5-120 min, and PI3-K signalling was investigated by immunoblot for total and phosphorylated Akt (S473). No phosphorylation of Akt (S473) was detected following CXCL1 stimulation $(100 \mathrm{ng} / \mathrm{ml})$ above basal levels at any of the time points investigated (data not shown), suggesting that although CXCL1 transactivates the EGFR, it does not activate PI3-K signalling and is unlikely to induce a positive feedback loop to activate its own production.

\section{CXCL1-stimulated proliferation involves Ras and MAPK signalling}

To investigate possible signalling pathways downstream of the EGFR, SKOV3 cells were treated with recombinant CXCL1 (100 $\mathrm{ng} / \mathrm{ml})$ for 5-120 min. Phosphorylation of ERK1/2 was seen after CXCL1 stimulation, with a 2.5 -fold increase in phosphorylated ERK1/2 observed after 15 min of CXCL1 treatment $(P<0.001)$, returning to basal levels by $120 \mathrm{~min}$ (Fig. 4A). A 30-min pretreatment of SKOV3 cells with the MEK1 inhibitor PD98059 $(10 \mu \mathrm{M})$ completely inhibited both basal and CXCL1-induced ERK1/2 phosphorylation (Fig. 4A). To determine whether CXCL1-induced MAPK signalling occurred upstream or downstream of the EGFR, SKOV3 cells were treated for $120 \mathrm{~min}$ with recombinant CXCL1 $(100 \mathrm{ng} / \mathrm{ml})$ either in the presence or absence of the MEK1 inhibitor PD98059 $(10 \mu \mathrm{M})$, and lysates were probed for EGFR tyrosine phosphorylation at Y1068. As observed previously (Fig. 3C), CXCL1 induced EGFR phosphorylation at Y1068; however, there was no effect of PD98059 on CXCL1-induced EGFR phosphorylation indicating that CXCL1-induced EGFR transactivation likely occurs upstream of MAPK signalling (Fig. 4B). Treatment of SKOV3 cells with either the pan-MMP inhibitor GM6001 or the EGFR inhibitor PD153035 inhibited CXCL1induced phosphorylation of ERK1/2, confirming that CXCL1-induced ERK1/2 activation occurred downstream of EGFR transactivation (Supplementary Figure 5, see section on supplementary data given at the end of this article).

To determine the role of MAPK signalling in CXCL1-induced proliferation, SKOV3 and OVCAR3 cells were treated with CXCL1 $(100 \mathrm{ng} / \mathrm{ml})$ in the presence of the MEK1 inhibitor PD98059 $(10 \mu \mathrm{M})$ and cell proliferation assessed over 7 days. Treatment of both cell lines with PD98059 completely inhibited CXCL1-induced proliferation $(P<0.0001)$, without affecting basal proliferation (Fig. 5A and B). In addition, the involvement of Ras in CXCL1-induced proliferation was assessed by treatment of SKOV3 and OVCAR-3 cells with CXCL1 in the presence of the $\mathrm{H}-$ and K-Ras-specific inhibitor, FTI-277 $(10 \mu \mathrm{M})$. CXCL1-induced proliferation was completely blocked by treatment with FTI-277 in both cell lines studied (Fig. 5C and D; $P<0.0001$ ). There was also an 


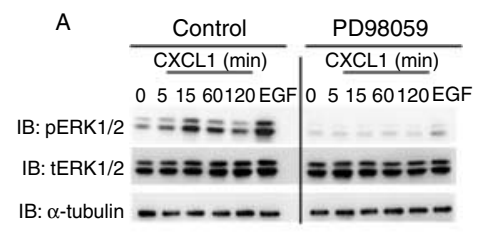

B
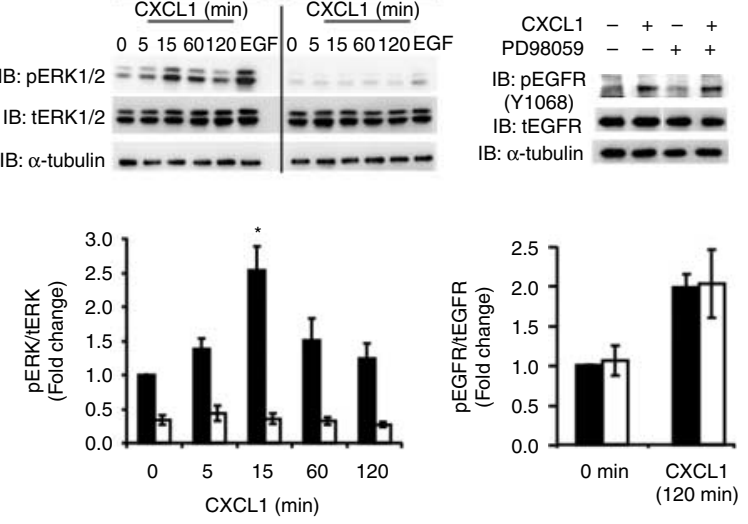

Figure 4 CXCL1 induces EGFR phosphorylation independent of ERK1/2 transactivation. (A) Immunoblot for phosphorylated ERK1/2 (pERK1/2), total ERK1/2 (tERK1/2) and $\alpha$-tubulin expression of serum-deprived SKOV3 cells pretreated with (open bars) or without (closed bars) the MEK1 inhibitor, PD98059 $(10 \mu \mathrm{M})$, for 30 min before treatment with CXCL1 $(100 \mathrm{ng} / \mathrm{ml})$ for $5-120 \mathrm{~min}$. A 5-min treatment with EGF ( $50 \mathrm{ng} / \mathrm{ml}$ ) was used as a positive control for ERK1/2 phosphorylation. Graph represents pooled data from four independent experiments with data calculated as $\mathrm{pERK} / \mathrm{tERK}$ ratios and expressed as fold change relative to untreated control \pm S.E.M. A 2.5-fold increase in pERK1/2 was observed 15 min after CXCL1 treatment, with both basal and CXCL1induced ERK1/2 phosphorylation completely inhibited by PD98059, ${ }^{\star} P<0.001$. (B) Immunoblot for pEGFR (Y1068), tEGFR and $\alpha$-tubulin of SKOV3 cells pretreated with (open bars) or without (closed bars) PD98059 $(10 \mu \mathrm{M})$ and treated with CXCL1 $(100 \mathrm{ng} / \mathrm{ml})$ for $120 \mathrm{~min}$. Graph represents pooled data from three independent experiments, with data calculated as $p E G F R / t E G F R$ ratios and expressed as fold change relative to untreated control \pm s.E.M. CXCL1-induced EGFR phosphorylation was unaffected by MEK1 inhibition.

inhibitory effect upon basal proliferation by FTI-277 in SKOV3 cells $(P<0.0001)$ but not in OVCAR-3 cells (Fig. 5C and D). These data indicate that CXCL1induced proliferation in EOC cells involves signalling through Ras and MEK1.

\section{CXCL1-stimulated proliferation occurs via MMP-mediated release of HB-EGF}

One mechanism of transactivation of the EGFR in response to ligands of various GPCRs involves MMPmediated release of membrane-bound EGFR ligands, such as HB-EGF (Prenzel et al. 1999, Itoh et al. 2005). To investigate the involvement of this mechanism in CXCL1-induced proliferation, SKOV3 and OVCAR-3 cells were treated with CXCL1 $(100 \mathrm{ng} / \mathrm{ml})$ in the presence of the pan-MMP inhibitor GM6001 (200 nM). CXCL1-induced proliferation was completely abolished in both cell lines after inhibition of MMP activity, with no effect on basal proliferation $(P<0.0001$; Fig. 6A and B). Similarly, treatment of cell lines with an HB-EGF neutralising antibody $(4 \mu \mathrm{g} / \mathrm{ml})$ in combination with recombinant CXCL1 $(100 \mathrm{ng} / \mathrm{ml})$ completely inhibited CXCL1-induced proliferation in both EOC cell lines (day 7, $P<0.0001$ ), again without affecting the basal proliferation rate (Fig. 6C and D). Isotype control $\mathrm{IgG}$ had no effect upon CXCL1-induced proliferation (data not shown). These data indicate that CXCL1-induced proliferation in EOC cells relies upon MMP-mediated cleavage of the membrane-bound EGFR ligand HB-EGF. In further support of this extracellular signalling mechanism, treatment of either cell line with recombinant CXCL1 did not lead to changes in phosphorylation of either the active (Y416) or inactive (Y527) forms of Src suggesting that CXCL1 does not activate intracellular signalling via $\mathrm{Src}$ (data not shown). Moreover, we have shown that EGFR phosphorylation at Y845, a site at which phosphorylation is mediated by c-Src, does not occur in response to treatment with CXCL1 (Supplementary Figure 4).
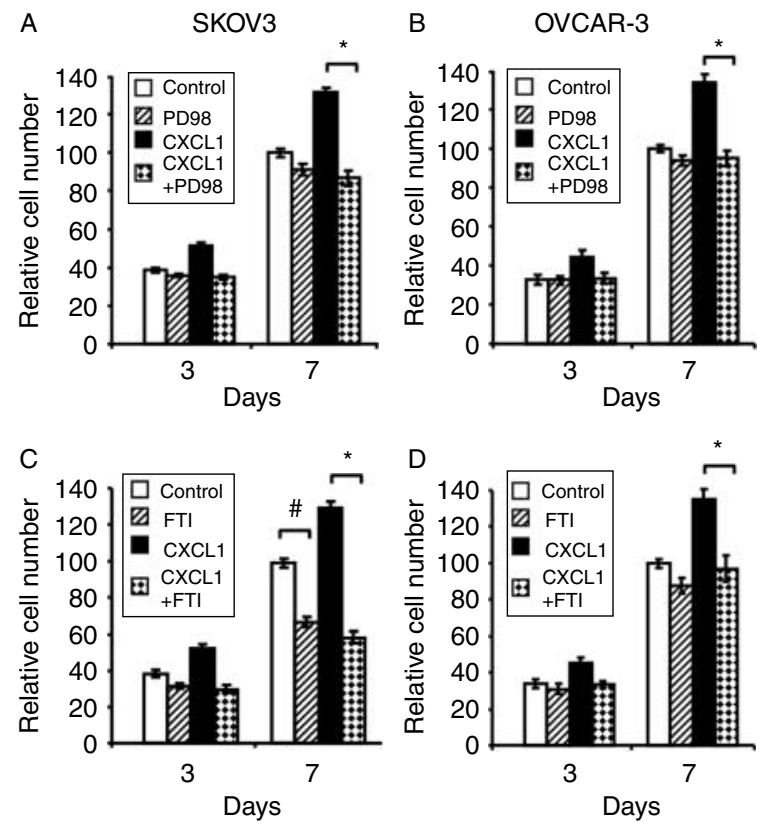

Figure 5 CXCL1-induced proliferation requires MEK1 and Ras activity. Effect of MEK1 inhibition by PD98059 $(10 \mu \mathrm{M})(\mathrm{A}$ and B) and $\mathrm{H}$ - and $\mathrm{K}-$ Ras inhibition by FTI-277 $(10 \mu \mathrm{M})(\mathrm{C}$ and $\mathrm{D})$ upon CXCL1-induced proliferation over 7 days in SKOV3 (A and C) and OVCAR-3 (B and D) cells was assessed. Graphs represent pooled data from four independent experiments expressed as relative cell number \pm S.E.M. where total cell number in the untreated control at day 7 is expressed as 100 . Inhibition of both MEK1 and Ras decreased CXCL1-induced proliferation in both cell lines indicating involvement of these pathways in CXCL1induced EOC proliferation. Treatment with FTI-277 also resulted in an inhibitory effect upon basal proliferation in SKOV3 cells (C), ${ }^{\star} P<0.0001,{ }^{\sharp} P<0.0001$. 

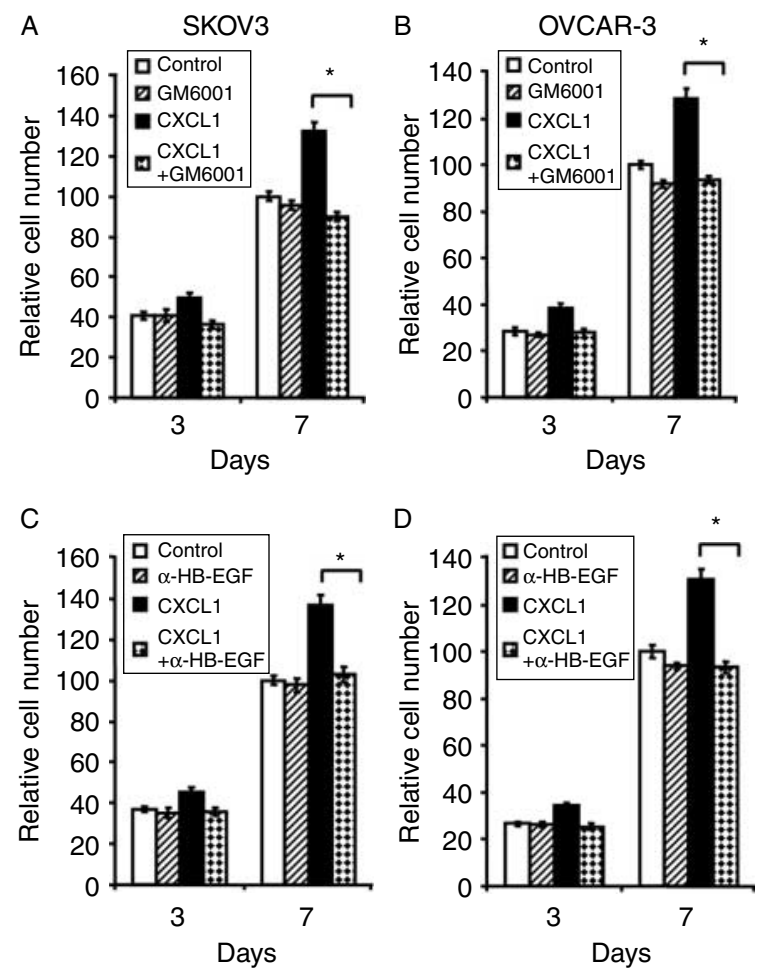

Figure 6 CXCL1-induced proliferation is mediated via MMP cleavage of HB-EGF. The involvement of MMP cleavage of HB-EGF in CXCL1-induced proliferation over 7 days was assessed in SKOV3 (A and C) and OVCAR-3 (B and D) cells. Graphs represent pooled data from four independent experiments with data expressed as relative cell number \pm S.E.M. where total cell number in the untreated control at day 7 is expressed as 100. Inhibition of MMP activity with GM6001 $(200 \mathrm{nM})(\mathrm{A}$ and $\mathrm{B})$ or an $\alpha$-HB-EGF neutralising antibody $(4 \mu \mathrm{g} / \mathrm{ml})(C$ and $D)$ decreased $C X C L 1$-induced proliferation in both cell lines, indicating involvement of MMP cleavage of HB-EGF in CXCL1-mediated proliferation of EOC, ${ }^{\star} P<0.0001$.

\section{Discussion}

We previously used a proteomic screen to identify CXCL1 as a chemokine regulated by PI3-K signalling in EOC cells (Moscova et al. 2006). Others have shown that CXCL1 levels are increased in serum, plasma, tumour tissue and ascites from women with ovarian cancer (Lee et al. 2006, Yang et al. 2006, Wang et al. 2008) suggesting a role for CXCL1 in ovarian cancer. Here, we have investigated whether elevated levels of CXCL1 have an autocrine role in EOC cells by influencing cell growth. Overexpression of CXCL1 increased cellular proliferation over 7 days in two ovarian cancer cell lines, SKOV3 and OVCAR-3. Conversely, down-regulation of CXCL1 in these cell lines inhibited cell proliferation, this effect being reversed by exogenous recombinant CXCL1. These data demonstrating a growth stimulatory activity of CXCL1 are in agreement with studies in other cancer cell types including melanoma (Richmond et al. 1983, 1985, Bordoni et al. 1989,1990, Shattuck et al. 1994, Luan et al. 1997), squamous cell carcinomas (Loukinova et al. 2000), colon (Li et al. 2004), oesophageal (Wang et al. 2006) and oral cancers (Shintani et al. 2004).

CXCL1 binds and signals through the GPCR, CXCR2 (Mueller et al. 1994), as confirmed by our demonstration that blocking CXCR2 with SB225002 inhibited CXCL1-induced proliferation. There is considerable evidence to support the existence of crosstalk between GPCRs and receptor tyrosine kinases. Transactivation of the EGFR by a number of GPCR ligands has been demonstrated, including thrombin, angiotensin, lysophosphatidic acid (Rozengurt 2007, Bhola \& Grandis 2008) and IL8, in many tissue types (Schraufstatter et al. 2003, Itoh et al. 2005, Luppi et al. 2007) including ovarian cancer (Venkatakrishnan et al. 2000).

IL8 signals through both the CXCL1 receptor CXCR2 and the related receptor CXCR1 (Lee et al. 1992); however, a previous study in ovarian cancer did not identify which receptor mediated IL8 transactivation of the EGFR (Venkatakrishnan et al. 2000). In the present study, we investigated whether CXCL1 may also induce EGFR transactivation and lead to increased ovarian cancer cell proliferation. CXCL1 stimulation of SKOV3 cells increased phosphorylation of the EGFR at Y1068, and inhibition of the EGFR by PD153035 decreased both CXCL1-induced phosphorylation of the EGFR at Y1068 and cell proliferation, suggesting that CXCL1-induced proliferation of EOC cells occurs through transactivation of the EGFR.

In our previous study, we found that EGF activation of the PI3-K pathway, leading to Akt phosphorylation, induced expression of CXCL1 (Moscova et al. 2006), suggesting a possible positive feedback loop where CXCL1 may regulate its own production through EGFR signalling. Since Akt pathway activity is associated with cell survival (Qiao et al. 2008), such a positive feedback might be strongly tumorigenic. However, phosphorylation of Akt at S473 was not detected following CXCL1 treatment, despite EGFR activation, indicating that a CXCL1-induced positive feedback loop through the PI3-K pathway is unlikely.

Chemokines have been well described to activate several pathways in addition to PI3-K signalling, such as the MAPK/ERK1/2 pathway (Venkatakrishnan et al. 2000, Xia \& Hyman 2002, Wang et al. 2006, Rozengurt 2007, Waugh \& Wilson 2008). CXCL1 induced ERK1/2 phosphorylation, which was blocked by the MEK1 inhibitor, PD98059. Furthermore, inhibition of CXCL1-induced ERK1/2 phosphorylation was inhibited by inhibition of the EGFR with 
PD153035 and the pan-MMP inhibitor GM6001, suggesting that CXCL1-induced ERK1/2 activation occurred downstream of transactivation of the EGFR. The involvement of MAPK signalling in CXCL1induced proliferation of EOC was further demonstrated by the inhibition of proliferation of EOC by both PD98059 and the farnesyltransferase inhibitor FTI-277, which blocks Ras activity (Lerner et al. 1995). Activation of ERK $1 / 2$ by CXCL1 has previously been reported in other cell types including astrocytes (Filipovic \& Zecevic 2008), neutrophils (Fuhler et al. 2005) and neurons (Xia \& Hyman 2002). IL8 has also been shown to stimulate ERK1/2 phosphorylation in SKOV3 cells (Venkatakrishnan et al. 2000). Given that IL8 and CXCL1 can signal through a common receptor, CXCR2, it is perhaps not surprising that treatment of cells with CXCL1 also leads to increased ERK1/2 phosphorylation. Cellular proliferation mediated by MAPK signalling has been well described (Rozengurt 2007), but this is the first report to describe the involvement of MAPK signalling in CXCL1-induced proliferation of EOC.

Our data suggest that transactivation of the EGFR by CXCL1 leads to activation of MAPK signalling, given that a peak of CXCL1-induced Y1068 EGFR phosphorylation was seen at $5 \mathrm{~min}$, prior to the peak of ERK1/2 phosphorylation. Inhibition of MEK1 activity had no effect on EGFR phosphorylation, also consistent with MAPK activation occurring downstream of the EGFR (Meloche \& Pouyssegur 2007). A second, slower wave of EGFR tyrosine phosphorylation seen 1-2 $\mathrm{h}$ after CXCL1 addition was not reflected in a second wave of ERK1/2 phosphorylation, suggesting that ERK phosphatases may still be active at this time. One mechanism of activation of MAPK signalling through GPCRs is mediated through the protein kinase C (PKC) pathway (Rozengurt 2007). We have recently described gonadotropin-induced EOC cell migration and proliferation through ERK1/2 activation, regulated by PKC $\delta$ (Mertens-Walker et al. 2010). It is therefore possible that PKCs may also play a role in CXCL1induced MAPK signalling.

Transactivation of the EGFR can be mediated either by intracellular signalling via Src (Andreev et al. 2001, Guerrero et al. 2004, Li et al. 2006) or through extracellular MMP-mediated release of EGFR ligands such as TGF- $\alpha$ (McCole et al. 2002), amphiregulin (Gschwind et al. 2003) or HB-EGF (Prenzel et al. 1999, Itoh et al. 2005). The lack of effect of CXCL1 on Src phosphorylation, the lack of activation of phosphorylation at the Y845 site of EGFR known to be mediated by $\mathrm{Src}$ and the inhibitory effect of the pan-MMP inhibitor GM6001 on CXCL1-induced cell proliferation all suggest that CXCL1-induced EGFR transactivation is mediated through the extracellular signalling pathway.

Recently, HB-EGF has been implicated as a promising target for therapy for many cancer types, including ovarian cancer (Miyamoto et al. 2004, Yagi et al. 2005, 2008, Yotsumoto et al. 2008). Treatment of both SKOV3 and OVCAR-3 cells with an antiHB-EGF neutralising antibody inhibited CXCL1induced cell proliferation, confirming this potential mechanism of EGFR transactivation by CXCL1. Consistent with this is the demonstration of MMP release of HB-EGF to transactivate the EGFR by IL8 in both colon carcinoma (Itoh et al. 2005) and endothelial cells (Schraufstatter et al. 2003). It is possible that other EGFR ligands, apart from HB-EGF, will also have roles in CXCL1-mediated cellular proliferation of ovarian cancer.

In summary, our results have shown that CXCL1 induces EOC cell proliferation and that this occurs through CXCR2 activation, HB-EGF release from the plasma membrane by an MMP-like enzyme, EGFR autophosphorylation and Ras-ERK activation. Since both in vitro (Moscova et al. 2006) and in vivo (Lee et al. 2006, Yang et al. 2006, Wang et al. 2008) studies suggest a role for CXCL1 in EOC, our findings point to potential therapeutic targets for this disease.

\section{Supplementary data}

This is linked to the online version of the paper at http://dx. doi.org/10.1677/ERC-10-0107.

\section{Declaration of interest}

The authors declare that there is no conflict of interest that could be perceived as prejudicing the impartiality of the research reported.

\section{Funding}

This work was supported by the Cancer Council NSW (Grant ID: 402640), the Cancer Institute NSW, Australia (Fellowship to D J Marsh), and the Watson Ovarian Cancer Research Fund.

\section{References}

Andreev J, Galisteo ML, Kranenburg O, Logan SK, Chiu ES, Okigaki M, Cary LA, Moolenaar WH \& Schlessinger J 2001 Src and Pyk2 mediate G-protein-coupled receptor activation of epidermal growth factor receptor (EGFR) but are not required for coupling to the mitogen-activated protein (MAP) kinase signaling cascade. Journal of Biological Chemistry 276 20130-20135. (doi:10.1074/ jbc.M102307200) 
Balkwill F 2004 Cancer and the chemokine network. Nature Reviews. Cancer 4 540-550. (doi:10.1038/nrc1388)

Baron-Hay S, Boyle F, Ferrier A \& Scott C 2004 Elevated serum insulin-like growth factor binding protein-2 as a prognostic marker in patients with ovarian cancer. Clinical Cancer Research 10 1796-1806. (doi:10.1158/ 1078-0432.CCR-0672-2)

Bast RC Jr, Klug TL, St John E, Jenison E, Niloff JM, Lazarus H, Berkowitz RS, Leavitt T, Griffiths CT, Parker L et al. 1983 A radioimmunoassay using a monoclonal antibody to monitor the course of epithelial ovarian cancer. New England Journal of Medicine 309 883-887. (doi:10.1056/NEJM198310133091503)

Bhola NE \& Grandis JR 2008 Crosstalk between G-proteincoupled receptors and epidermal growth factor receptor in cancer. Frontiers in Bioscience 13 1857-1865. (doi:10. 2741/2805)

Bordoni R, Thomas G \& Richmond A 1989 Growth factor modulation of melanoma growth stimulatory activity mRNA expression in human malignant melanoma cells correlates with cell growth. Journal of Cellular Biochemistry 39 421-428. (doi:10.1002/jcb.240390408)

Bordoni R, Fine R, Murray D \& Richmond A 1990 Characterization of the role of melanoma growth stimulatory activity (MGSA) in the growth of normal melanocytes, nevocytes, and malignant melanocytes. Journal of Cellular Biochemistry 44 207-219. (doi:10.1002/jcb.240440403)

Carpenter G 1999 Employment of the epidermal growth factor receptor in growth factor-independent signaling pathways. Journal of Cell Biology 146 697-702. (doi:10. 1083/jcb.146.4.697)

Carpenter G 2000 EGF receptor transactivation mediated by the proteolytic production of EGF-like agonists. Science's STKE : Signal Transduction Knowledge Environment 2000 PE1. (doi:10.1126/scisignal.152000pe1)

Dannenmann C, Shabani N, Friese K, Jeschke U, Mylonas I \& Bruning A 2008 The metastasis-associated gene MTA1 is upregulated in advanced ovarian cancer, represses ERbeta, and enhances expression of oncogenic cytokine GRO. Cancer Biology \& Therapy 7 1460-1467.

Filipovic R \& Zecevic N 2008 The effect of CXCL1 on human fetal oligodendrocyte progenitor cells. Glia $\mathbf{5 6}$ 1-15. (doi:10.1002/glia.20582)

Fuhler GM, Knol GJ, Drayer AL \& Vellenga E 2005 Impaired interleukin-8- and GROalpha-induced phosphorylation of extracellular signal-regulated kinase result in decreased migration of neutrophils from patients with myelodysplasia. Journal of Leukocyte Biology 77 257-266. (doi:10.1189/jlb.0504306)

Fung ET 2010 A recipe for proteomics diagnostic test development: the OVA1 test, from biomarker discovery to FDA clearance. Clinical Chemistry 56 327-329. (doi:10.1373/clinchem.2009.140855)

Gschwind A, Hart S, Fischer OM \& Ullrich A 2003 TACE cleavage of proamphiregulin regulates GPCR-induced proliferation and motility of cancer cells. EMBO Journal 22 2411-2421. (doi:10.1093/emboj/cdg231)
Guerrero J, Santibanez JF, Gonzalez A \& Martinez J 2004 EGF receptor transactivation by urokinase receptor stimulus through a mechanism involving Src and matrix metalloproteinases. Experimental Cell Research 292 201-208. (doi:10.1016/j.yexcr.2003.08.011)

Itoh Y, Joh T, Tanida S, Sasaki M, Kataoka H, Itoh K, Oshima T, Ogasawara N, Togawa S, Wada T et al. 2005 IL-8 promotes cell proliferation and migration through metalloproteinase-cleavage proHB-EGF in human colon carcinoma cells. Cytokine 29 275-282. (doi:10.1016/j. cyto.2004.11.005)

Jacobs I \& Bast RC Jr 1989 The CA 125 tumour-associated antigen: a review of the literature. Human Reproduction 4 1-12.

Jacobs IJ \& Menon U 2004 Progress and challenges in screening for early detection of ovarian cancer. Molecular \& Cellular Proteomics 3 355-366. (doi:10.1074/mcp. R400006-MCP200)

Karstrom-Encrantz L, Runesson E, Bostrom EK \& Brannstrom M 1998 Selective presence of the chemokine growth-regulated oncogene alpha (GROalpha) in the human follicle and secretion from cultured granulosalutein cells at ovulation. Molecular Human Reproduction 4 1077-1083. (doi:10.1093/molehr/4.11.1077)

Kozak KR, Su F, Whitelegge JP, Faull K, Reddy S \& Farias-Eisner R 2005 Characterization of serum biomarkers for detection of early stage ovarian cancer. Proteomics 5 4589-4596. (doi:10.1002/pmic.200500093)

Lambeck AJ, Crijns AP, Leffers N, Sluiter WJ, ten Hoor KA, Braid M, van der Zee AG, Daemen T, Nijman HW \& Kast WM 2007 Serum cytokine profiling as a diagnostic and prognostic tool in ovarian cancer: a potential role for interleukin 7. Clinical Cancer Research 13 2385-2391. (doi:10.1158/1078-0432.CCR-06-1828)

Lee J, Horuk R, Rice GC, Bennett GL, Camerato T \& Wood WI 1992 Characterization of two high affinity human interleukin-8 receptors. Journal of Biological Chemistry 267 16283-16287.

Lee Z, Swaby RF, Liang Y, Yu S, Liu S, Lu KH, Bast RC Jr, Mills GB \& Fang X 2006 Lysophosphatidic acid is a major regulator of growth-regulated oncogene alpha in ovarian cancer. Cancer Research 66 2740-2748. (doi:10. 1158/0008-5472.CAN-05-2947)

Lerner EC, Qian Y, Blaskovich MA, Fossum RD, Vogt A, Sun J, Cox AD, Der CJ, Hamilton AD \& Sebti SM 1995 Ras CAAX peptidomimetic FTI-277 selectively blocks oncogenic Ras signaling by inducing cytoplasmic accumulation of inactive Ras-Raf complexes. Journal of Biological Chemistry 270 26802-26806. (doi:10.1074/ jbc.270.45.26802)

Li A, Varney ML \& Singh RK 2004 Constitutive expression of growth regulated oncogene (gro) in human colon carcinoma cells with different metastatic potential and its role in regulating their metastatic phenotype. Clinical \& Experimental Metastasis 21 571-579. (doi:10.1007/ s10585-004-5458-3)

Li Z, Hosoi Y, Cai K, Tanno Y, Matsumoto Y, Enomoto A, Morita A, Nakagawa K \& Miyagawa K 2006 Src tyrosine 
kinase inhibitor PP2 suppresses ERK1/2 activation and epidermal growth factor receptor transactivation by $\mathrm{X}$-irradiation. Biochemical and Biophysical Research Communications 341 363-368. (doi:10.1016/j.bbrc.2005. 12.193)

Liebmann C 2010 EGF receptor activation by GPCRs: an universal pathway reveals different versions. Molecular and Cellular Endocrinology [in press]. (doi:10.1016/j. mce.2010.04.008)

Loukinova E, Dong G, Enamorado-Ayalya I, Thomas GR, Chen Z, Schreiber H \& Van Waes C 2000 Growth regulated oncogene-alpha expression by murine squamous cell carcinoma promotes tumor growth, metastasis, leukocyte infiltration and angiogenesis by a host CXC receptor-2 dependent mechanism. Oncogene 19 3477-3486. (doi:10.1038/sj.onc.1203687)

Luan J, Shattuck-Brandt R, Haghnegahdar H, Owen JD, Strieter R, Burdick M, Nirodi C, Beauchamp D, Johnson KN \& Richmond A 1997 Mechanism and biological significance of constitutive expression of MGSA/GRO chemokines in malignant melanoma tumor progression. Journal of Leukocyte Biology 62 588-597.

Luppi F, Longo AM, de Boer WI, Rabe KF \& Hiemstra PS 2007 Interleukin-8 stimulates cell proliferation in nonsmall cell lung cancer through epidermal growth factor receptor transactivation. Lung Cancer 56 25-33. (doi:10. 1016/j.lungcan.2006.11.014)

McCole DF, Keely SJ, Coffey RJ \& Barrett KE 2002 Transactivation of the epidermal growth factor receptor in colonic epithelial cells by carbachol requires extracellular release of transforming growth factor-alpha. Journal of Biological Chemistry 277 42603-42612. (doi:10.1074/ jbc.M206487200)

Meloche S \& Pouyssegur J 2007 The ERK1/2 mitogenactivated protein kinase pathway as a master regulator of the $\mathrm{G}_{1}$ - to S-phase transition. Oncogene 26 3227-3239. (doi:10.1038/sj.onc.1210414)

Mertens-Walker I, Bolitho C, Baxter RC \& Marsh DJ 2010 Gonadotropin-induced ovarian cancer cell migration and proliferation require extracellular signal-regulated kinase $1 / 2$ activation regulated by calcium and protein kinase C \{delta\}. Endocrine-Related Cancer 17 335-349. (doi:10.1677/ERC-09-0152)

Miyamoto S, Hirata M, Yamazaki A, Kageyama T, Hasuwa H, Mizushima H, Tanaka Y, Yagi H, Sonoda K, Kai M et al. 2004 Heparin-binding EGF-like growth factor is a promising target for ovarian cancer therapy. Cancer Research 64 5720-5727. (doi:10.1158/0008-5472.CAN-04-0811)

Moscova M, Marsh DJ \& Baxter RC 2006 Protein chip discovery of secreted proteins regulated by the phosphatidylinositol 3-kinase pathway in ovarian cancer cell lines. Cancer Research 66 1376-1383. (doi:10.1158/00085472.CAN-05-2666)

Mueller SG, Schraw WP \& Richmond A 1994 Melanoma growth stimulatory activity enhances the phosphorylation of the class II interleukin-8 receptor in non-hematopoietic cells. Journal of Biological Chemistry 269 1973-1980.
Nosov V, Su F, Amneus M, Birrer M, Robins T, Kotlerman J, Reddy S \& Farias-Eisner R 2009 Validation of serum biomarkers for detection of early-stage ovarian cancer. American Journal of Obstetrics and Gynecology 200 639.e1-639.e5. (doi:10.1016/j.ajog.2008.12.042)

Oral E, Seli E, Bahtiyar MO, Jones EE \& Arici A 1997 Growth-regulated alpha expression in human preovulatory follicles and ovarian cells. American Journal of Reproductive Immunology 38 19-25.

Parkin DM, Bray F, Ferlay J \& Pisani P 2005 Global cancer statistics, 2002. CA: A Cancer Journal for Clinicians 55 74-108. (doi:10.3322/canjclin.55.2.74)

Prenzel N, Zwick E, Daub H, Leserer M, Abraham R, Wallasch C \& Ullrich A 1999 EGF receptor transactivation by G-protein-coupled receptors requires metalloproteinase cleavage of proHB-EGF. Nature 402 884-888. (doi:10.1038/47260)

Qiao M, Sheng S \& Pardee AB 2008 Metastasis and AKT activation. Cell Cycle 7 2991-2996.

Richmond A \& Thomas HG 1988 Melanoma growth stimulatory activity: isolation from human melanoma tumors and characterization of tissue distribution. Journal of Cellular Biochemistry 36 185-198. (doi:10. 1002/jcb.240360209)

Richmond A, Lawson DH, Nixon DW, Stevens JS \& Chawla RK 1983 Extraction of a melanoma growth-stimulatory activity from culture medium conditioned by the $\mathrm{Hs} 0294$ human melanoma cell line. Cancer Research $\mathbf{4 3}$ 2106-2112.

Richmond A, Lawson DH, Nixon DW \& Chawla RK 1985 Characterization of autostimulatory and transforming growth factors from human melanoma cells. Cancer Research 45 6390-6394.

Rozengurt E 2007 Mitogenic signaling pathways induced by $\mathrm{G}$ protein-coupled receptors. Journal of Cellular Physiology 213 589-602. (doi:10.1002/jcp.21246)

Schafer B, Marg B, Gschwind A \& Ullrich A 2004 Distinct ADAM metalloproteinases regulate $G$ protein-coupled receptor-induced cell proliferation and survival. Journal of Biological Chemistry 279 47929-47938. (doi:10.1074/jbc.M400129200)

Schildkraut JM \& Thompson WD 1988 Familial ovarian cancer: a population-based case-control study. American Journal of Epidemiology 128 456-466.

Schraufstatter IU, Trieu K, Zhao M, Rose DM, Terkeltaub RA \& Burger M 2003 IL-8-mediated cell migration in endothelial cells depends on cathepsin B activity and transactivation of the epidermal growth factor receptor. Journal of Immunology 171 6714-6722.

Shattuck RL, Wood LD, Jaffe GJ \& Richmond A 1994 MGSA/GRO transcription is differentially regulated in normal retinal pigment epithelial and melanoma cells. Molecular and Cellular Biology 14 791-802.

Shayesteh L, Lu Y, Kuo WL, Baldocchi R, Godfrey T, Collins C, Pinkel D, Powell B, Mills GB \& Gray JW 1999 PIK3CA is implicated as an oncogene in ovarian cancer. Nature Genetics 21 99-102. (doi:10.1038/5042) 
Shintani S, Ishikawa T, Nonaka T, Li C, Nakashiro K, Wong DT \& Hamakawa H 2004 Growth-regulated oncogene-1 expression is associated with angiogenesis and lymph node metastasis in human oral cancer. Oncology 66 316-322. (doi:10.1159/000078333)

Venkatakrishnan G, Salgia R \& Groopman JE 2000 Chemokine receptors CXCR-1/2 activate mitogenactivated protein kinase via the epidermal growth factor receptor in ovarian cancer cells. Journal of Biological Chemistry 275 6868-6875. (doi:10.1074/jbc.275.10. 6868)

Wang B, Hendricks DT, Wamunyokoli F \& Parker MI 2006 A growth-related oncogene/CXC chemokine receptor 2 autocrine loop contributes to cellular proliferation in esophageal cancer. Cancer Research 66 3071-3077. (doi:10.1158/0008-5472.CAN-05-2871)

Wang Q, Zhang W, Li D \& Li L 2008 Identification of two potential serum biomarkers for ovarian cancer and clinical validation thereof. Zhonghua Yi Xue Za Zhi 88 1012-1016.

Waugh DJ \& Wilson C 2008 The interleukin-8 pathway in cancer. Clinical Cancer Research 14 6735-6741. (doi:10. 1158/1078-0432.CCR-07-4843)

Xia M \& Hyman BT 2002 GROalpha/KC, a chemokine receptor CXCR2 ligand, can be a potent trigger for neuronal ERK1/2 and PI-3 kinase pathways and for tau hyperphosphorylation - a role in Alzheimer's disease? Journal of Neuroimmunology 122 55-64. (doi:10.1016/ S0165-5728(01)00463-5)

Yagi H, Miyamoto S, Tanaka Y, Sonoda K, Kobayashi H, Kishikawa T, Iwamoto R, Mekada E \& Nakano H 2005 Clinical significance of heparin-binding epidermal growth factor-like growth factor in peritoneal fluid of ovarian cancer. British Journal of Cancer 92 1737-1745. (doi:10. 1038/sj.bjc.6602536)

Yagi H, Yotsumoto F \& Miyamoto S 2008 Heparin-binding epidermal growth factor-like growth factor promotes transcoelomic metastasis in ovarian cancer through epithelialmesenchymal transition. Molecular Cancer Therapeutics 7 3441-3451. (doi:10.1158/1535-7163.MCT-08-0417)

Yang G, Rosen DG, Zhang Z, Bast RC Jr, Mills GB, Colacino JA, Mercado-Uribe I \& Liu J 2006 The chemokine growth-regulated oncogene 1 (Gro-1) links RAS signaling to the senescence of stromal fibroblasts and ovarian tumorigenesis. PNAS 103 16472-16477. (doi:10.1073/ pnas.0605752103)

Yotsumoto F, Yagi H, Suzuki SO, Oki E, Tsujioka H, Hachisuga T, Sonoda K, Kawarabayashi T, Mekada E \& Miyamoto S 2008 Validation of HB-EGF and amphiregulin as targets for human cancer therapy. Biochemical and Biophysical Research Communications 365 555-561. (doi:10.1016/j.bbrc.2007.11.015) 